\title{
Nutritional surveillance: experiences from developing countries
}

\author{
B Y S. J . ISMA I L \\ London School of Hygiene and Tropical Medicine, Keppel Street, London WCIE 7HT
}

\begin{abstract}
Resolution V (paragraph 13) of the World Food Conference held in 1974 (United Nations, 1975) called for '. . . a global nutritional surveillance system to be established by the Food and Agriculture Organization (FAO), the World Health Organization (WHO) and the United Nations International Children's Emergency Fund (UNICEF) to monitor the food and nutrition conditions of the disadvantaged groups of the population at risk, and to provide a method of rapid and permanent assessment of all factors which influence food consumption patterns and nutritional status'. WHO was designated the lead agency and a Joint FAO/UNICEF/WHO Expert Committee met in 1975 to develop a methodology of nutritional surveillance. The Committee recognized (World Health Organization, 1976) that for a global system to exist, action was needed first to develop national systems and second that information from these systems should be such as to permit international comparisons. It should be noted, however, that the international agencies, in line with their mandated role as information providers, had already issued, and continue to issue, a number of global reports presenting economic, social, health and agricultural indicators that could be seen as contributing to a global nutritional surveillance system. Examples of these reports are International Labour Organization's publications on Basic Needs, WHO's World Health Statistics Bulletins, UNICEF's State of the World's Children reports, and FAO's Food Balance Sheets, World Food Surveys and reports on food crops and shortages.
\end{abstract}

In 1977, the Subcommittee on Nutrition (SCN) was established under the United Nations (UN)'s Administration and Coordination Committee (ACC), with a responsibility for reporting periodically on the world nutrition situation. In 1987 the ACC/SCN published the First Report on the World Nutrition Situation which represents an initial attempt to bring together national economic, food supply and nutritional status data, and to show global and regional trends over the previous 25 years.

It goes without saying that the quality of the information presented in all such global reports depends entirely on the quality and availability of national-level data. FAO, for example, does not collect its own food supply data; such data are provided by the countries themselves, hopefully using the standard methodology developed by FAO. Similarly, the ACC/SCN's attempts at global nutritional surveillance, the first report (United Nations Administrative Committee on Coordination/Subcommittee on $\mathrm{Nu}$ trition, 1987) in 1987 and the update (United Nations Administrative Committee on Coordination/Subcommittee on Nutrition, 1989) in 1989, reflect national experiences in the area of nutritional surveillance, and are constrained quantitatively and qualitatively by such experiences.

The period immediately following the 1974 World Food Conference was a period of considerable activity with regard to attempts to establish national food and nutrition surveillance systems. The concept of nutritional surveillance itself arose from the concept (and perceived success) of disease surveillance. Many of the elements of a nutritional surveillance system existed in most developing countries. Countries have monitored their 
food supplies and economic conditions for centuries; the weighing and measuring of individuals has also existed for a long time, occasionally to present a picture of the condition of a particular group of people, such as army recruits, but rarely, until recently, on a national level. Surveys to collect information on nutritional status and food consumption of populations or particular subgroups of populations have been conducted during this century but have proved on the whole to be expensive exercises and difficult to sustain on a regular basis. Furthermore, in the absence of adequate computer facilities, data from national surveys in particular were generally available too late to be of any real use to decision-making.

Clinic-based growth monitoring has existed for a long time, serving generally on an individual basis as a diagnostic and management tool and more recently as a way to improve a mother's understanding of the growth and development of her child (Gerein, 1988). Growth monitoring data aggregated to the community, regional and national levels have been used as a component of nutrition surveillance systems; indeed, in some countries, Zimbabwe, Zambia and Swaziland, for example, (UNICEF, 1984), growth monitoring information is the only component of the surveillance system.

In 1974, therefore, most countries had in place at least some of the elements of a nutritional surveillance system; the challenges facing nutritionists in developing countries were on the one hand, to bring together these various elements so as to create a coherent system of regular information gathering upon which policy and programming decisions could be based, and on the other hand to persuade decision-makers of the usefulness of such information. It is important to remember that the 1970 s was also the decade of nutrition planning. The challenges and obstacles faced by proponents of nutrition planning were similar in many respects to those encountered when faced with the task of establishing a national nutrition surveillance system: the need for multi-sectoral collaboration, the low priority accorded to nutrition, the need for the nutritionist to assume the role of advocate. Perhaps also the failure of many surveillance systems reflects the failure of many nutrition planning efforts.

During the $1970 \mathrm{~s}$, nutrition surveillance activities were strongly supported by bilateral donors, in particular USAID and SIDA, as well as by the international agencies (Mason et al. 1984). Academic institutions in developed countries were often involved in providing technical assistance and training. The most active of these was Cornell University in the USA, with its USAID-funded Cornell Nutritional Surveillance Program. Throughout the 1970 s, national early-warning systems were developed with support from FAO and a number of bilateral donors to forecast local food shortages using crop monitoring, rainfall and price data. During the late 1970s and continuing into the 1980s, nutritional status monitoring was included as a component of some earlywarning systems. Of these, the most notable experiences were those of Botswana, Ethiopia and Indonesia (United Nations Administrative Committee on Coordination/ Subcommittee on Nutrition, 1982). During the early 1980s concern for the negative effects of economic recession and structural adjustment policies created another potential role for nutritional surveillance, namely that of monitoring the impact of these events and policies on the poorer sections of society. Indeed, the case studies in UNICEF's (1987) study Adjustment with a Human Face, relied heavily on national surveillance information (Cornia \& Stewart, 1987; Stewart, 1987) to describe the nutritional impact of structural adjustment policies. Also in 1987, the FAO/WHO/ UNICEF Interagency Food and Nutrition Surveillance Programme was launched, with 
UNICEF as the key fund raiser. The Programme has proved only partially successful, with bilateral donors more willing to fund national projects directly than to contribute to an elaborate interagency exercise.

The Report of the 1976 Joint FAO/UNICEF/WHO Expert Committee (World Health Organization, 1976) describes nutritional surveillance as a continuous process that should have five specific objectives. Briefly, these objectives are:

(1) to describe the nutritional status of the population, with particular reference to those at risk;

(2) to analyse the causes and associated factors of malnutrition;

(3) to promote decisions by governments regarding both normal development and emergencies;

(4) to predict the probable evolution of nutritional problems so as to assist in policy formulation;

(5) to monitor and evaluate nutritional programmes.

To these objectives could now be added two more, namely the monitoring of national policies, such as structural adjustment policies, and the contribution to global nutritional surveillance. Mason et al. (1984) describe three main types of surveillance systems:

(1) long-term nutritional monitoring as an input to national planning, to analyse the effects of policies and to predict future trends; the response to such information is slow, often in line with national planning cycles;

(2) evaluation of the nutritional impact of specific programmes and projects; information designed to permit more immediate responses through programme or project modification;

(3) early-warning or timely warning systems to identify acute food shortages, generally due to crop failures, in order to permit rapid short-term responses.

In practice, however, the distinction among the three types is not clear. Many systems begin with the intent to serve more than one purpose. The extent to which they succeed is not always evident. In particular, the extent to which the information is used for the purposes intended, or indeed if it is used at all, is very difficult to assess; unbiased evaluations of the usefulness and use of surveillance information are rare.

The specific uses for nutritional surveillance information range from the relatively simple one of deciding where to implement a supplementary feeding programme to the much more ambitious one of guiding national development policies and plans. These uses can be described as follows:

\section{Deciding where to implement simple nutrition interventions, such as supplementary feeding or nutrition education programmes}

Examples of surveillance systems that seem to serve only this purpose are those of Lesotho, Swaziland, Zambia, Zimbabwe (UNICEF, 1984). They are based almost exclusively on clinic-based growth-monitoring data and can be viewed simply as an extension of growth-monitoring activities. At district and central levels they serve at best to identify those communities or districts that are likely to have the highest levels of malnutrition. However, clinic attenders are generally not representative of the population (Gerein, 1988): coverage may be low, children brought to clinics may be very sick, 
or they may be from better-educated families who see the need for immunization, and there is certainly an age bias with more younger children attending than older ones. Also, in the absence of any attempt to relate anthropometric data to other data, no analysis of causal or associated factors is possible.

\section{Deciding when and where to initiate food aid}

Examples of early-warning systems that include a nutrition component are the Food Information System of Ethiopia, Botswana's Food and Nutrition Information System and Indonesia`s Early Warning and Intervention System.

Ethiopia's early-warning activities began in 1975 when it established the Consolidated Food and Nutrition Information System (United Nations Administrative Committee on Coordination/Subcommittee on Nutrition, 1982), within the Relief and Rehabilitation Commission (RRC). Monthly crop status, rainfall and price data were collected and, when these indicated a deteriorating situation in a particular geographical area, ad hoc surveys were undertaken through the Disaster Area Assessment System. On occasion, these surveys included the collection of child anthropometric data. In addition, the Ethiopian Nutrition Institute undertook a number of anthropometric surveys in the Ogaden area (Gebre-Medhin et al. 1977).

By the early 1980s, some non-governmental organizations (NGO), in particular Save the Children Fund (SCF), had established a variety of nutritional monitoring systems, progressively covering most of the drought-prone regions of the country, except Eritrea, Tigre and some parts of northern Wollo. Data from the various NGO were generally not comparable.

In 1986, the externally funded Food Information System project began, with technical inputs from FAO. The objective of the project was to expand and improve the early-warning system with, inter alia, the addition of a nutrition component. The project, based at the Central Statistical Office (CSO), produced extensive biannual reports on the food situation, while the RRC continued to produce monthly early-warning bulletins. A standard method of collecting and reporting nutritional monitoring data was developed and accepted by all NGO undertaking such activities. From 1987, the CSO biannual reports included compiled NGO nutrition data. The reports, however, made no effort to integrate the nutrition with the early-warning data. It seems likely also that the nutrition data were poorly understood by food aid donors. perhaps equally poorly by the nutritionists themselves, and that no decisions were taken that would not have been taken on the basis of the early-warning data only.

There has been some debate about the value and interpretation of nutritional status data in early-warning systems. Two unpublished reports were prepared (in 1988 by J. Appleton, SCF and in 1991 by M. Kelly, Overseas Development Agency) examining the role of nutritional status survey data in famine early warning and relief targeting in the Wollo region of Ethiopia, 1982-88. Attempts have also been made to integrate nutritional status data with agricultural data (Mason et al. 1987) for Botswana. At this stage, the most that we can say is that in Ethiopia nutritional status data are unlikely to give earlier warning for an impending food shortage than crop monitoring and rainfall, but that nutritional status may deteriorate before prices rise. In Botswana nutritional status deteriorated about 6 months after adverse changes in computed maize and livestock indices were recorded. 
External funding for Ethiopia's Food Information System Project ended in 1989, and the System was discontinued, although the RRC continued to provide early-warning bulletins as it had done in the 1970s. Yet another national nutritional surveillance system is now in the planning stage, this time based in the Ministry of Planning with technical and funding support from UNICEF, CSO and the Ethiopian Nutrition Institute.

Botswana's Food and Nutrition Information System has received considerable attention in the literature. Established in the early 1970 s as an early-warning system, with a clinic-based nutritional status component added in 1978, the system produces monthly reports which are reviewed by three multi-sectoral committees: the Early Warning Technical Committee, the Inter-ministerial Drought Committee and the National Food Security Working Group. V. Quinn (Nutritional Surveillance: A Review of Recent Experiences in Eastern and Southern Africa; an unpublished document produced in 1986) has stated that the information is used not only for drought monitoring but also for the 'long-term planning of the country's food and nutrition strategies'. Quinn has identified also an institutional link in that individuals from the Rural Development Unit of the Ministry of Finance and Planning chair all three committees. It should be noted, however, that the role of nutritional status data is to monitor the impact of drought, and not to provide early warning of drought. The system appears to be well-established and has clearly played a key role in drought management, but Quinn has given no specific examples of long-term planning decisions that have been influenced by the system's information.

Indonesia's system (UNICEF, 1983) was established to predict famines in order to permit rapid initiation of relief actions. As in Botswana, it combines clinic-based nutritional status data with crop production and rainfall data, supplemented, however, by socio-economic information on unemployment, beggars and prostitution. As an early-warning system, it would seem to be functioning efficiently, with responses including not only the provision of food but also the initiation of public works projects.

\section{Formulation of food and nutrition policies and plans and inputs to sectoral planning}

The majority of national surveillance systems were established with policy formulation and planning as primary objectives: twenty of twenty-four systems reviewed were established with these stated objectives. It seems possible that information provided by the systems of Costa Rica, Kenya, Philippines and Sri Lanka provided at least some guidance in the formulation of national nutrition policies and plans. Less clear, however, is the extent to which the information influenced decision-making in the agricultural sector or in overall national development planning. In Kenya, it may have occurred. The Central Bureau of Statistics undertakes household surveys every 2 or 3 years which, since 1977, have included a child nutrition module. Haaga et al. (1986) used a geographical and agricultural classification to describe the prevalence pattern of child malnutrition in rural Kenya. Kenya's Food and Nutrition Planning Unit (FNPU) is located in the Ministry of Planning and Development and as such is well-situated to influence national planning. Quinn, however, in the report referred to earlier, has mentioned specifically only the use of surveillance information by donor agencies and by FNPU in planning a district-level integrated nutrition programme.

Costa Rica's Nutrition Information System is interesting in that much effort was devoted to multi-sectoral participation while the system was being planned (Payne \& 
Thomson, 1981; Valverde et al. 1981). This certainly generated interest in nutrition issues, and subsequently the information provided by the system may have played a part in nutritional advocacy. The use of nutritional surveillance information, however, has been largely limited to the area of social policy; in fact the system is now based in the Office of Control of Family Welfare.

India's National Nutrition Monitoring Bureau (NNMB) was established in 1972 at the National Institute of Nutrition (UNICEF, 1983), and continued to operate until 1983. Extensive nutritional status, dietary and clinical data and some limited socio-economic information on 400 rural and 250 urban households were collected through annual surveys in each of ten states. While the data may have been used for programme evaluation, they have not been used for national development planning. In 1987 central planners involved in the preparation of India's development plan stated that the sample size per state was too small when disaggregated by socio-economic group (personal communication). Indeed, poor utilization of the information has been identified as one of the weaknesses of NNMB activities (UNICEF, 1983), and may have been partially responsible for their cessation.

Finally, in discussing nutritional surveillance systems, a brief mention should be made of the fact that there is considerable debate on the choice of indicators to be used in surveillance systems (Habicht, 1980). Questions of validity, specificity, interpretation, cost and ease of data collection have been raised, not all of which have been resolved. Perhaps the problems experienced by developing countries when planning and implementing surveillance systems are as much related to these unresolved issues as they are to the question of why have a system at all?

The literature is substantial on why nutritional surveillance systems should be established, and how to establish them. Critical and unbiased evaluations of exactly how surveillance information has actually been used for national policy decisions, planning or programme management are singularly lacking. The only clearly identifiable user is the international community, in the preparation of global reports such as the First report on the World Nutrition Situation (United Nations Administrative Committee on Coordination/Subcommittee on Nutrition, 1987) or UNICEF's study of the impact of structural adjustment (Cornia \& Stewart, 1987). Surveillance information may also contribute to project identification, generally, however, for externally-funded projects. Certainly information from early-warning systems has been used to trigger a food aid response; it is unlikely, however, that including a nutritional status component can or does significantly improve the timing or targeting of the response. Most countries originally established their surveillance systems with funding from bilateral donors or international agencies. Should we now urge countries to continue to support the systems from scarce national resources if indeed the international community is the single most important user? Perhaps at the very least we should pause to undertake the much-needed evaluations of existing nutritional surveillance systems.

\section{REFERENCES}

('ornia, G. A. \& Stewart, F. (1987). Country experience with adjustment. In Adjustment with a Human Face. pp. 105-127 [G. A. Cornia, R. Jolly and F. Stewart, editors]. Oxford: Clarendon Press.

Gebre-Medhin, M., Hay, R., Licke, Y. \& Maff, M. (1977). III Initial experience of a consolidated food and nutrition information system. Analysis of data from the Ogaden area. Environmental Child Health 23, 29-36. 
Gerein, N. (1988). Is growth monitoring worthwhile? Health Policy and Planning 3, 181-194.

Haaga, J., Mason, J., Omoro, F. Z., Quinn, V., Rafferty, A., Test. K. \& Wasonga, L. (1986). Child malnutrition in rural Kenya: A geographic and agricultural classification. Ecology of Food and Nutrition 18 , 297-307.

Habicht, J.-P. (1980). Some characteristics of indicators of nutritional status for use in screening and surveillance. American Journal of Clinical Nutrition 33, 531-535.

Mason, J. B., Haaga, J. G., Maribe, T. O., Marks, G., Quinn, V. J. \& Test, K. E. (1987). Using agricultural data for timely warning to prevent the effects of drought on child nutrition in Botswana. Ecology of Food and Nutrition 19, 169-184.

Mason, J. B., Habicht, J.-P., Tabatabai, H. \& Valverde, V. (1984). Nutritional Surveillance. Gencva: WHO.

Payne, P. R. \& Thomson, A. M. (1981). Setting up a nutrition information system: the Costa Rican example. Monitoring and Evaluation of Rural development. Rome: FAO.

Stewart, F. (1987). Monitoring and statistics for adjustment with a human face. In Adjustment with a Human Face, pp. 257-272 [G. A. Cornia, R. Jolly and F. Stewart. editors]. Oxford: Clarendon Press.

UNICEF (1983). Working Papers: Regional Workshop on Nutrition Surveillance, Bangkok, Thailand. 7-9 November 1983. New York: UNICEF.

UNICEF (1984). Report on the Botswana Workshop on Clinic-based Nutritional Surveillance Systems and Integrated Data Bases, Gabarone, Botswana, 10-12 January 1984. UNICEF Social Statistics Programme 7 (1). Nairobi: UNICEF - EARO.

United Nations (1975). Report of the World Food Conference, Rome, 5-6 November 1974. Publication E/Conf. 65/20. New York: UN.

United Nations Administrative Committee on Coordination/Subcommittce on Nutrition (1982). Report of the International Workshop on Nutritional Surveillance, Cali, Colombia, 14-17 July 1981. Rome: ACC/SCN.

United Nations Administrative Committee on Coordination/Subcommittee on Nutrition (1987). First Report on the World Nutrition Situation. Rome: ACC/SCN.

United Nations Administrative Committee on Coordination/Subcommittee on Nutrition (1989). Update on the Nutrition Situation - Recent Trends in Nutrition in 33 Countries. Geneva: ACC/SCN.

Valverde, V., Rojas, Z., Vinocur, P., Payne, P. \& Thomson, A. (1981). Organization of an information system for food and nutrition programmes in Costa Rica. Food and Nutrition 7, 32-40

World Health Organization (1976). Methodology of Nutritional Surveillance. Report of a Joint FAO/UNICEF/ WHO Expert Committee, Technical Report Series no. 593. Geneva: WHO. 